\title{
Improving phytosterol biotransformation at low nitrogen levels by enhancing the methylcitrate cycle with transcriptional regulators PrpR and GInR of Mycobacterium neoaurum
}

Yang Zhang ${ }^{1,2^{*}+}$, Xiuling Zhou ${ }^{1 \dagger}$, Xuemei Wang ${ }^{1}$, Lu Wang ${ }^{1}$, Menglei Xia ${ }^{1}$, Jianmei Luo ${ }^{1}$, Yanbing Shen ${ }^{1 *}$ and Min Wang ${ }^{1 *}$ (D)

\begin{abstract}
Background: Androstenedione (AD) is an important steroid medicine intermediate that is obtained via the degradation of phytosterols by mycobacteria. The production process of $A D$ is mainly the degradation of the phytosterol aliphatic side chain, which is accompanied by the production of propionyl CoA. Excessive accumulation of intracellular propionyl-CoA produces a toxic effect in mycobacteria, which restricts the improvement of production efficiency. The 2-methylcitrate cycle pathway (MCC) plays a significant role in the detoxification of propionyl-CoA in bacterial. The effect of the MCC on phytosterol biotransformation in mycobacteria has not been elucidated in detail. Meanwhile, reducing fermentation cost has always been an important issue to be solved in the optimizing of the bioprocess.

Results: There is a complete MCC in Mycobacterium neoaurum (MNR), prpC, prpD and prpB in the prp operon encode methylcitrate synthase, methylcitrate dehydratase and methylisocitrate lyase involved in MCC, and PrpR is a specific transcriptional activator of prp operon. After the overexpression of $\operatorname{prpDCB}$ and $\operatorname{prpR}$ in $M N R$, the significantly improved transcription levels of $p r p C$, prpD and prpB were observed. The highest conversion ratios of AD obtained by MNR-prpDBC and MNR-prpR increased from $72.3 \pm 2.5 \%$ to $82.2 \pm 2.2 \%$ and $90.6 \pm 2.6 \%$, respectively. Through enhanced the PrpR of MNR, the in intracellular propionyl-CoA levels decreased by $43 \pm 3 \%$, and the cell viability improved by $22 \pm 1 \%$ compared to MNR at $96 \mathrm{~h}$. The nitrogen transcription regulator GlnR repressed prp operon transcription in a nitrogen-limited medium. The $g / n R$ deletion enhanced the transcription level of $p r p D B C$ and the biotransformation ability of MNR. MNR-prpR/ $\Delta g / n R$ was constructed by the overexpression of $p r p R$ in the $g / n R$-deleted strain showed adaptability to low nitrogen. The highest AD conversion ratio by MNR-prpR/ $\Delta g \ln R$ was $92.8 \pm 2.7 \%$ at low nitrogen level, which was 1.4 times higher than that of MNR.
\end{abstract}

\footnotetext{
*Correspondence: zhy@lcu.edu.cn; shenyb@tust.edu.cn; minw@tust.edu.cn

†Yang Zhang and Xiuling Zhou contributed equally to this work

${ }^{1}$ Key Laboratory of Industrial Fermentation Microbiology, Ministry

of Education, Tianjin Key Laboratory of Industrial Microbiology,

College of Biotechnology, Tianjin University of Science \& Technology,

Tianjin 300457, China

${ }^{2}$ College of Life Science, Liaocheng University, Liaocheng 252059,

Shandong, China
}

(C) The Author(s) 2020. This article is licensed under a Creative Commons Attribution 4.0 International License, which permits use, sharing, adaptation, distribution and reproduction in any medium or format, as long as you give appropriate credit to the original author(s) and the source, provide a link to the Creative Commons licence, and indicate if changes were made. The images or other third party material in this article are included in the article's Creative Commons licence, unless indicated otherwise in a credit line to the material. If material is not included in the article's Creative Commons licence and your intended use is not permitted by statutory regulation or exceeds the permitted use, you will need to obtain permission directly from the copyright holder. To view a copy of this licence, visit http://creativeco mmons.org/licenses/by/4.0/. The Creative Commons Public Domain Dedication waiver (http://creativecommons.org/publicdomain/ zero/1.0/) applies to the data made available in this article, unless otherwise stated in a credit line to the data. 


\begin{abstract}
Conclusion: Improvement in phytosterol biotransformation after the enhancement of propionyl-CoA metabolism through the combined modifications of the prp operon and $g \ln R$ of mycobacteria was investigated for the first time. The overexpress of prpR in MNR can increase the transcription of essential genes (prpC, prpD and prpB) of MCC, reduce the intracellular propionyl-CoA level and improve bacterial viability. The knockout of glnR can enhance the adaptability of MNR to the nitrogen source. In the MNR $\Delta g \ln R$ strain, overexpress of $p r p R$ can achieve efficient production of $A D$ at low nitrogen levels, thus reducing the production cost. This strategy provides a reference for the economic and effective production of other valuable steroid metabolites from phytosterol in the pharmaceutical industry.
\end{abstract}

Keywords: Mycobacterium neoaurum, Androstenedione, Methylcitrate cycle, Transcriptional regulator, Nitrogen level

\section{Background}

Steroid drugs are widely used in anti-inflammation, endocrine regulation, and fertility management [1]. The global market for steroidal drugs has exceeded $\$ 10$ billion, and the industry prospects are extensive [2]. Microbial biotransformation using phytosterols as substrates has become an important way to produce steroid precursors, such as androstenedione (AD) and $9 \alpha$-hydroxyandrostenedione (9 $\alpha-\mathrm{OH}-\mathrm{AD})$ [3]. Phytosterols mainly exist in plants and are abundant in crops, such as beans and cereals, which are starting materials for steroid drugs production through mycobacterium transformation because of their low cost and environment-friendly attributes [4]. The gene-editing of the sterol side chain degradation metabolic pathway has made the industrial production of the steroidal pharmaceutical precursor by phytosterol biotransformation possible [5-11], but on the premise of improving production efficiency, reducing production costs is still the continuous pursuit of industrial production. Recently, studies on toxic metabolites, such as reactive oxygen species (ROS) in the production process of strains, have provided new ideas for the study of phytosterol conversion $[12,13]$.

The production of $\mathrm{AD}$ and $9 \alpha-\mathrm{OH}-\mathrm{AD}$ from phytosterol bioprocessing mainly involves the degradation of aliphatic side chains through $\beta$-oxidation, and several propionyl-Coenzyme A (CoA) and acetyl-CoA are produced [14-16]. For example, when $\beta$-sitosterol is used as the substrate, the complete degradation of the side chain will produce three molecules of propionyl-CoA and one molecule of acetyl-CoA [17]. Propionyl-CoA plays an essential role in maintaining the balance of metabolic flow and energy supply during the metabolism of sterols and odd-chain fatty acids in mycobacteria [18]. Previous studies have shown that the excessive accumulation of intracellular propionyl-CoA in Mycobacterium smegmatis and $M$. tuberculosis produces a toxic effect, which seriously affects the growth of mycobacteria on propionate or mixtures of propionate and glucose $[19,20]$. Three different detoxification mechanisms in mycobacteria have been proposed, namely, the methylmalonyl cycle pathway (MMC), the 2-methylcitrate cycle pathway (MCC), and the incorporation of propionyl moieties into cell envelope methyl-branched lipids [20]. Our recent research shows that enhanced MMC in Mycobacterium neoaurum (MNR) promotes the conversion of propionyl-CoA to nontoxic succinyl-CoA and improves the transformation of phytosterols [21]. Therefore, while metabolizing propionyl-CoA, MCC also has the dual effects of detoxification and energy supply.

Previous findings have shown that in the MCC of mycobacteria, propionyl-CoA is converted to pyruvate at a molar ratio of 1:1 [22, 23]. The methylcitrate synthase (MCS or PrpC; encoded $\operatorname{prpC}$ ) catalyzes the condensation of propionyl-CoA with oxaloacetate to 2-methylcitrate, which is then dehydrated to produce methylaconitate. This step is accomplished by either methylcitrate dehydratase (MCD or PrpD; encoded prpD) or by the combined activity of methylcitrate dehydratase (AcnD) and methylaconitate cis-trans isomerase (PrpF). Following dehydration, methylaconitate is rehydrated by aconitase (AcnB) to yield methylisocitrate and cleaved by methylisocitrate lyase (MCL or PrpB; encoded $\operatorname{prp} B$ ) or by isocitrate lyase to produce pyruvate and succinate [24]. The prp operon plays a key role in the assimilation of propionyl-CoA in Mycobacterium tuberculosis [25], and Mycobacterium smegmatis [19] to obtain carbon and energy and prevents the accumulation of toxic metabolites. Masiewicz et al. [26] identified the novel transcription factor (PrpR; encoded prpR) that regulates the MCC by induces self-transcription and activating the prp operon in M. tuberculosis. PrpR is essential for the utilization of odd-chain-length fatty acids, and the $p r p R$ knockout strain exhibited an inhibited growth on propionate as a sole carbon source. Therefore, speculation is that the effector of PrpR may be propionyl-CoA, which is an intermediate metabolite of both odd-chain-length fatty acids and propionate.

Current research on MCC in mycobacteria is focused on Mycobacterium tuberculosis and Mycobacterium smegmatis, which are mainly related to the function of MCC at low cholesterol concentrations and other substrates. The effect of MCC on the transformation ability of steroid precursor production strains at a high 
concentration of phytosterol has not been reported, which is worthy of further study.

Nitrogen is an essential element for the microbial synthesis of proteins, nucleic acids, and substances required for growth. The supply of nitrogen sources strongly influences the growth and metabolism of heterotrophic microorganisms and autotrophic algae, which is very important for the efficient generation of target products during fermentation [27-30]. The nitrogen sources that can be absorbed and utilized by microorganisms in the fermentation industry are usually expensive yeast extract and peptone [31]. Therefore, finding an inexpensive alternative nitrogen source is the primary method to reduce the cost of the medium [32]. We have tried to use the hydrolysate of mycobacterial cells instead of yeast extract to reduce the cost of nitrogen source [21], but the relatively complex process limits its large-scale application in industrial production. Compared with the use of cheap nitrogen sources, improving the adaptability of strains to poor nitrogen sources is more direct and effective in reducing the cost of nitrogen sources.

Considerable research has shown that the utilization of nitrogen sources by microorganisms is controlled by regulatory proteins such as GlnR [33]. Studies on mycobacteria have shown that $G \ln R$ can regulate nitrogen assimilation in response to its limited availability [34]. GlnR is a conserved OmpR-like transcription factor, which is one of the regulators of nitrogen metabolism in actinomycetes, can regulate more than 100 genes, and has a wide range of effects on the growth and adaptation environment [35]. In a recent study, Liu et al. [36] found that GlnR directly binds to the promoter region of prpDBC and inhibits its transcription in M. smegmatis. However, little is known about the effects of regulatory factors, PrpR and GlnR, on the transformation of phytosterols by mycobacteria. Improving the nitrogen source adaptation level of a strain by nitrogen regulation factors is significant, and to the best of our knowledge, this process has not been reported.

In the present work, we show for the first time that genetically manipulating transcription factors can improve the AD production in a Mycobacterium. The transcriptional level of $\operatorname{prpDBC}$ and the changes in cell growth and $\mathrm{AD}$ production after the overexpression of $p r p R$ in MNR were studied. The effects of $g \ln R$ deletion on the transcription level of $\operatorname{prpDBC}$ and the $\mathrm{AD}$ molar conversion rates were investigated at different nitrogen source levels. To further improve the productivity of $\mathrm{AD}$, a $\operatorname{prpR}$ overexpressing strain MNR-prpR/AglnR was constructed under $g \ln R$ deletion, and the AD productivity of MNR-prpR/ $\Delta g \ln R$ at different nitrogen source levels was evaluated. In summary, strategies for effectively enhancing $\mathrm{AD}$ production by using prp operon and $g \ln R$ were first reported.

\section{Materials and methods \\ Mutant strains construction}

All modified strains and plasmids used in this work are listed in Table 1. Escherichia coli DH5 $\alpha$ was used for plasmid replication. Genes overexpression and deletion methods have been reported in previous studies [21]. In MNR, the vector pMV261 having kanamycin resistance $\left(\operatorname{Kan}^{R}\right)$ was used to overexpress the target gene. Genes of PrpR and PrpDBC were amplified from the genome of MNR. The prpR and $\operatorname{prpDBC}$ genes were recombined with the linearized pMV261 using the In-Fusion HD Cloning method to generate recombinant plasmids, which were named pMV261-prpR and pMV261-prp$D B C$, respectively. The recombinant plasmid introduced to MNR through electroporation to gain the recombinant strains (MNR-prpR and MNR-prpDBC). The empty plasmid control strain (MNR-pMV261) was constructed by the introduction of pMV261 into the MNR. The inframe deletion mutants of $g \ln R$ were built by referring to the methods of Yao et al. [22]. The $1131 \mathrm{bp}$ upstream sequence and 1107 bp downstream sequence of $g \ln R$ were obtained as a recombinant fragment by PCR. Two fragments were ligated into the plasmid P2NIL and then digested with PacI and ligated with a selection marker cassette from pGoal19 to construct a homologous recombinant plasmid. The constructed plasmid was transferred into mycobacterial cells by electroporation, and the $\ln R$ knockout strain was screened according to the previously reported protocol [11]. Construction of recombinant strains MNR-prpR/ $\Delta g \ln R$ and MNR-prpDBC/ $\Delta g \ln R$ by electroporation of plasmids pMV261-prpR and pMV261$\operatorname{prp} D B C$ into MNR $\triangle g \ln R$.

\section{Medium and cultivation conditions}

All reagents and substrates were prepared as previously described $[13,21]$. E. coli $\mathrm{DH} 5 \alpha$ was cultured at $37{ }^{\circ} \mathrm{C}$ in Luria-Bertani (LB) medium $(10.0 \mathrm{~g} / \mathrm{L}$ tryptone, $5.0 \mathrm{~g} / \mathrm{L}$ yeast extract, and $10 \mathrm{~g} / \mathrm{L} \mathrm{NaCl}$ at $\mathrm{pH} 7.0$ ), where appropriate, kanamycin was added to the medium with a final concentration of $50 \mu \mathrm{g} / \mathrm{mL}$. Mycobacteria seeds were prepared according to the previous description [21]. Seeds were inoculated into a shake flask containing $50 \mathrm{~mL}$ of fermentation medium at $10 \%$ inoculation for phytosterol bioconversion and then cultured for $168 \mathrm{~h}$ at $30{ }^{\circ} \mathrm{C}$ and $200 \mathrm{rpm}$. The phytosterol biotransformation medium ( $\mathrm{pH} 7.5)$ contained $10 \mathrm{~g} / \mathrm{L}$ glucose, $2.0 \mathrm{~g} / \mathrm{L}$ $\left(\mathrm{NH}_{4}\right)_{2} \mathrm{HPO}_{4}, 0.05 \mathrm{~g} / \mathrm{L}$ ferric ammonium citrate, $0.25 \mathrm{~g} / \mathrm{L}$ $\mathrm{MgSO}_{4}, 25 \mathrm{mM}$ hydroxypropyl- $\beta$-cyclodextrin, and $5 \mathrm{~g} / \mathrm{L}$ phytosterol. The normal nitrogen source level was set to $1\left(\mathrm{~N}^{1}\right)$, and one-tenth $\left(\mathrm{N}^{0.1}\right)$, one-half $\left(\mathrm{N}^{0.5}\right)$, three-fifths 
Table 1 Strains, plasmids, and primers used in this study

\begin{tabular}{|c|c|c|}
\hline Strains, plasmids, and primers & Significant properties & Source or purpose \\
\hline \multicolumn{3}{|l|}{ Strains } \\
\hline E. coli DH5a & General cloning host & Transgen Biotech \\
\hline $\begin{array}{l}\text { Mycobacterium neoaurum TCCC } \\
11,978 \text { (MNR) }\end{array}$ & Wild type & $\begin{array}{l}\text { Tianjin University of Science and } \\
\text { Technology Culture Collection } \\
\text { Center (TCCC) }\end{array}$ \\
\hline MNR-prpR & prpR overexpressed strain of MNR & This work \\
\hline MNR-prpDBC & prpDBC overexpressed strain of MNR & This work \\
\hline$M N R \Delta g \ln R$ & Deletion of $g \ln R$ in MNR & This work \\
\hline$M N R \triangle g \ln R:: g \ln R$ & $g \ln R$ complemented in MNR $\triangle \mathrm{g} \ln R$ & This work \\
\hline MNR-prpR/ $\Delta g \ln R$ & prpR over-expressed strain of MNR $\triangle \mathrm{g} \ln R$ & This work \\
\hline MNR-prpDBC/ $\triangle g \ln R$ & prpDBC over-expressed strain of MNR $\triangle \mathrm{g} \ln R$ & This work \\
\hline MNR-pMV261 & MNR carrying vector pMV261 & This work \\
\hline \multicolumn{3}{|l|}{ Plasmids } \\
\hline pMV261 & $\begin{array}{l}\text { Shuttle vector of mycobacterium and E. coli, carrying the heat shock hsp60 } \\
\text { promoter, } \operatorname{Kan}^{R}\end{array}$ & Dr. W. R. Jacobs Jr \\
\hline $\mathrm{p} 2 \mathrm{NIL}$ & Plasmid for allelic exchange, non-replicative in Mycobacterium species, $\mathrm{Kan}^{R}$ & Dr. T. Parish \\
\hline pGOAL19 & lacZ, hyg and $s a c B$ marker genes cassette-containing vector, $\mathrm{Hyg}^{R}$ & Dr. T. Parish \\
\hline pMV261-prpR & pMV261 carrying an extra prpR for overexpression, $\mathrm{Kan}^{R}$ & This work \\
\hline pMV261-prpDBC & pMV261 carrying an extra prpDBC for overexpression, $\mathrm{Kan}^{R}$ & This work \\
\hline pMV261-gln $R$ & pMV261 carrying an extra glnR for overexpression, $K n^{R}$ & This work \\
\hline pKO-glnR & $\begin{array}{l}\text { P2NILcarrying the homologous arms of } g \ln R \text { and the selection markers from } \\
\text { PGOAL19 }\end{array}$ & This work \\
\hline \multicolumn{3}{|l|}{ Primers } \\
\hline \multicolumn{3}{|l|}{ PCR for overexpression } \\
\hline $\operatorname{prpR-f}$ & GGATCCAGCTGCAGAATTCGTGGCGAAGACATTCGCGGG & prpR amplification \\
\hline $\operatorname{prpR-r}$ & CGCTAGTTAACTACGTCGACTCAGTTGGCGGGCGGGTAGG & prpR amplification \\
\hline $\operatorname{prpDBC-f}$ & GGATCCAGCTGCAGAATTCGTGCGGATCATGCAGAAACA & prpDBC amplification \\
\hline $\operatorname{prpDBC-r}$ & CGCTAGTTAACTACGTCGACTCACCGGCGACGTTCCAGCG & prpDBC amplification \\
\hline \multicolumn{3}{|l|}{ PCR for deletion } \\
\hline$g \ln R-U-f$ & ATAAACTACCGCATTAAAGCTTTCTGAACCCGTCCAGGTCGA & gln $R$ deletion \\
\hline$g \ln R-U-R$ & CTCGGGACCGACGATCGCGATATCGGCG & gln $R$ deletion \\
\hline$g \ln R-D-f$ & ATCGTCGGTCCCGAGTACGAGGCGCTG & gln $R$ deletion \\
\hline$g \ln R-\mathrm{D}-\mathrm{R}$ & TGACACTATAGAATACATAGGATCCGGTCCGCGGACGGAAAGTGA & gln $R$ deletion \\
\hline \multicolumn{3}{|l|}{ For qRT-PCR } \\
\hline $16 s-f-R T / 16 s-r-R T$ & GTAGGGTCCGAGCGTTGTC/GCGTCAGTTACTGCCCAGAG & Quantitative RT-PCR \\
\hline$p r p R-\mathrm{f}-\mathrm{RT} / p r p R-\mathrm{r}-\mathrm{RT}$ & CCTGGGAACCCCGAAGA/GCCCGACATAGGGAAACG & Quantitative RT-PCR \\
\hline prpD-f-RT/prpD-r-RT & TGGTCAAGGGCATCTGTCTG/TGCCCGATGGCGTTGTA & Quantitative RT-PCR \\
\hline prpB-f-RT/prpB-r-RT & GACCAGGTGAACCCCAAGC/GCGGGCACAGATCACAAAG & Quantitative RT-PCR \\
\hline$p r p C-f-R T / p r p C-r-R T$ & GCCCAATCTGGATTTCCC/AGCGTTTGAAGCGGTTTG & Quantitative RT-PCR \\
\hline$g \ln R-f-R T / g \ln R-r-R T$ & CCTCGGGGAGTTGGTCAT/ GTTGGGCCAGATACTTCAGC & Quantitative RT-PCR \\
\hline
\end{tabular}

$\left(\mathrm{N}^{0.6}\right)$, seven-tenths $\left(\mathrm{N}^{0.7}\right)$, four-fifths $\left(\mathrm{N}^{0.8}\right)$, and ninetenths $\left(\mathrm{N}^{0.9}\right)$ of its weight were added to the fermentation medium to investigate the effects of different nitrogen source levels on the strain.

\section{Quantitative reverse transcription-PCR (qRT-PCR)}

For qRT-PCR analysis, the cells were cultured for $48 \mathrm{~h}$ and collected by centrifugation at $8,000 \times g$ for $10 \mathrm{~min}$ at $4{ }^{\circ} \mathrm{C}$. Isolation of RNA was carried out according to the method described by our previous description [13]. The qRT-PCR analysis was performed according to the previously described method [37]. The primers for qRT-PCR were listed in Table 1. The messenger RNA (mRNA) level of the 16S rRNA gene was used as the housekeeping gene (internal control) to normalize the sampling errors [38]. Relative gene expression levels 
were calculated by the comparative $\mathrm{Ct}$ method $\left(2^{-\Delta \Delta \mathrm{Ct}}\right.$ method) [39].

\section{Determination of intracellular propionyl-CoA concentrations}

During the fermentation of MNR, MNR-prpR and MNRprpDBC, samples were taken at 24-hour intervals, and the samples were divided equally. One part was used to detect the dry cell weight (DCW) according to the previous method [40], and the other was used to analyze intracellular propionyl-CoA. Intracellular propionyl-CoA levels were detected using a modified method previously described by Xu et al. [41]. Cells cultures were harvested and quenched in liquid nitrogen and washed twice with precooled phosphate-buffered saline (PBS, $\mathrm{pH}$ 8.0), then added with lysis buffer (10\% trichloroacetic acid and $2 \mathrm{mM}$ dithiothreitol), and repeatedly frozen and thawed four times using liquid nitrogen ice water, then sonicated on ice for 5 min (work $5 \mathrm{~s}$, stop $5 \mathrm{~s}$ ) using an ultrasonic disintegrator (JY96-IIN; Ningbo Xinzhi Instruments Inc., Ningbo, China). The supernatant was collected by centrifugation at $14,000 \times g$ for $10 \mathrm{~min}$ at $4{ }^{\circ} \mathrm{C}$ and transferred to an equilibrated solid-phase extraction column (SepPak, tC18; Waters, Milford, MA). After loading the sample, wash the extraction column with $0.1 \%$ trifluoroacetic acid (TFA). The extraction column was subsequently eluted with $40 \%$ acetonitrile containing $0.1 \%$ TFA. The collected eluent was freeze-drying performed in a freezedryer (Alpha 2-4 LD plus, Martin Christ, Osterode am Harz, Germany) and stored at $-80{ }^{\circ} \mathrm{C}$ until analysis.

For the analysis of propionyl-CoA, the prepared samples were assayed by high-performance liquid chromatography (HPLC) using Agilent 1260 (Agilent Technologies, Santa Clara, CA, U.S.A.) equipped with UV detection at $260 \mathrm{~nm}$. HPLC analysis was realized on a reversed-phase $\mathrm{C} 18$ column $(250 \mathrm{~mm} \times 4.6 \mathrm{~mm})$ at $25^{\circ} \mathrm{C}$, and the two mobile-phase solvents used were buffer $\mathrm{A}$ (acetonitrile) and buffer B (100 mM ammonium acetate, $\mathrm{pH}$ 5.8). The linear gradient elution was carried out at $0.8 \mathrm{~mL} / \mathrm{min}$, and elution condition was as follows: $2-12 \%$ A (0-5 min), $12-38 \%$ A (5-15 min), 38\% A (15-17 min), $38-2 \%$ A (17-19 min), data collection was stopped at $30 \mathrm{~min}$. The content of propionyl-CoA was calculated by the external standard method.

Propionyl-CoA (Sigma, USA) was used for the preparation of the standard curve. The standard stock solution of propionyl-CoA $(100 \mu \mathrm{mol} / \mathrm{L})$ was prepared and stored at $-80{ }^{\circ} \mathrm{C}$. Propionyl-CoA standard working solutions were prepared by diluting the stock solutions to $0.01,0.05$, $0.1,0.2,0.5,1,2,2.5,5.0$, and $10 \mu \mathrm{mol} / \mathrm{L}$. The calibration curve was prepared using the standard working solutions of propionyl-CoA. For each sample, the propionyl-CoA concentration was calculated by interpolating the sample measurement in the standard curve. Finally, the intracellular propionyl-CoA concentrations were calculated according to the DCW value of each sample.

\section{Detection of bacterial viability and product analysis}

The bacterial viability using the modified CCK- 8 method was determined as described previously [13]. The fermentation broth adjusts the $\mathrm{OD}_{600}$ value to 1 using a Tris- $\mathrm{HCl}$ buffer (pH 7.2). Add $190 \mu \mathrm{L}$ fermentation broth and $10 \mu \mathrm{L}$ of WST- 8 to the 96 -well plate, detect absorbance at $450 \mathrm{~nm}$ after $1 \mathrm{~h}$ incubate at $30{ }^{\circ} \mathrm{C}$. For product analysis, samples were taken every $24 \mathrm{~h}$ during the conversion of phytosterol, and the same volume of ethyl acetate was added to $1 \mathrm{~mL}$ fermentation broth for $30 \mathrm{~min}$. After $12,000 \times g$ centrifugation for $10 \mathrm{~min}, 200 \mu \mathrm{L}$ extract was dissolved in $80 \%$ methanol after vacuum drying and centrifuged at $12,000 \times g$ for $20 \mathrm{~min}$ for HPLC analysis. HPLC analysis was prepared according to the method described by the previous description [21].

\section{Results and discussion}

Sequence homology and function analysis of PrpR, PrpD, PrpB, PrpC and GInR

Previous studies confirm that $M$. smegmatis contains prpD, $\operatorname{prpD}$ and $\operatorname{prp} C$, but $M$. tuberculosis contains only $\operatorname{prpD}$ and $\operatorname{prp} C$. The activity of PrpB is provided by isocitrate lyases of $M$. tuberculosis (ICL1 and ICL2; encoded $i c l 1$ and icl2), which are two isoforms involved in the glyoxylate pathway. The amino acid sequence analysis showed that the PrpD, PrpB and PrpC of MNR were similar to $M$. smegmatis and $M$. tuberculosis with sequence identity between 76 and $88 \%$ (Fig. 1a). The sequence concordance between the PrpR of MNR and the transcription factor PrpR of $M$. smegmatis was $74 \%$. Sequence homology alignment results showed that MNR and 9a-OH-AD producing strain M. fortuitum (MFT) [13] had a complete MCC, and the similarity of each enzyme was higher than $82 \%$. Therefore, MCC is widely present in mycobacteria with phytosterol transformation ability. The analysis of the prpDBC upstream region revealed a typical PrpR binding motif (TTCGCAAA), and GlnR binding motif (GGACCGGCACCGTAAC) were observed in the upstream region of $\operatorname{prpDBC}$ in MNR (Fig. 1b). According to Liu et al. [36], GlnR directly binds to the promoter region of $\operatorname{prp} D B C$ and inhibits its transcription in $M$. smegmatis. So the same mechanism also exists in MNR.

\section{The function of prp gene cluster in MNR PrpR promotes the transcription of prpDBC in MNR}

The $\operatorname{prpR}$ and $\operatorname{prpDBC}$ overexpression strains (MNR$p r p R$ and MNR-prpDBC) were constructed for studying the effect of PrpR on $p r p D B C$ in MNR. The relative 


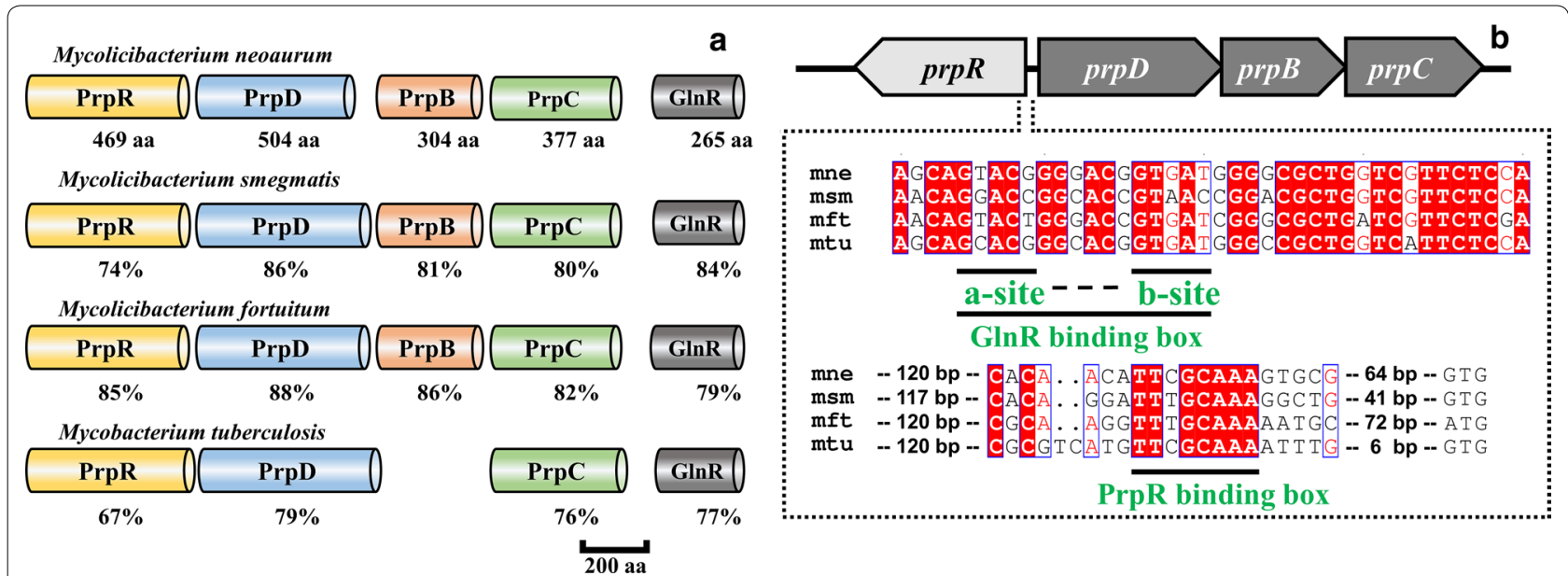

Fig. 1 Sequence homology and function analysis of PrpR, PrpD, PrpB, PrpC and GlnR of four mycobacteria. a The structural variations of the PrpR, $\operatorname{PrpD}$, PrpB, PrpC and GInR. $\mathbf{b} \mathrm{G} \ln R$ and PrpR bind the promoter region of $\operatorname{prpDBC}$ in M. neoaurum

transcription levels of $\operatorname{prpD}, \operatorname{prpB}$ and $\operatorname{prp} C$ in $\mathrm{MNR}$, MNR-prpR and MNR-prpDBC were compared in the presence of phytosterols. As shown in Fig. 2a, the relative transcription level of $\operatorname{prpDBC}$ increased significantly in the $\operatorname{prpR}$-overexpressed strain compared with that in the wild type strain. The $\operatorname{prpD}, \operatorname{prpB}$ and $\operatorname{prp} C$ transcripts increased in MNR-prpR $16.5 \pm 2.4-, 10.5 \pm 3.1-$ and $36.0 \pm 4.9$-fold, respectively. The overexpression of prp$D B C$ increased the transcription levels of $\operatorname{prpD}, \operatorname{prpB}$ and $\operatorname{prpC} 5.6 \pm 2.0$-, $6.5 \pm 2.8$ - and $5.3 \pm 2.0$-fold, respectively. Therefore, $\operatorname{prp} R$ is a positive transcription regulator of $\operatorname{prp} D B C$ in MNR. In addition, the relative transcription level of $p r p D$, $p r p B$ and $\operatorname{prpC}$ in strain MNR-prpR was higher than that in MNR-prpDBC. The reason may be that the PrpR protein produced by overexpression of $p r p R$ in MNR-prpR can promote the transcription of $\operatorname{prpD}, \operatorname{prpB}$ and $\operatorname{prp} C$ on the genome, and also promote the transcription of $\operatorname{prpR}$ gene, thus producing a dual promoting effect on $p r p D$, $\operatorname{prp} B$ and $p r p C$ transcription.
Therefore, as far as the relative transcription level of $\operatorname{prpD}, \operatorname{prp} B$ and $\operatorname{prp} C$ is concerned, overexpression of prpR alone has a better effect.

\section{Enhancement of $A D$ productivity by overexpressing the prp operon}

The effects of prp operon enhancement on cell growth and $\mathrm{AD}$ production were studied. It was found that the conversion rate of a single gene $(\operatorname{prpD}, \operatorname{prpB}$ and $\operatorname{prp} C$ ) overexpression was always lower than that of coexpression of three genes (data not shown). Therefore, the $\operatorname{prpR}$ and $\operatorname{prpDBC}$ overexpression strains (MNRprpR and MNR-prpDBC) were selected for comparative study with the parental strain (MNR) and the control strain (MNR-pMV261). Although all strains have the same growth trend, the introduction of plasmids could reduce the biomass, which is more pronounced when overexpressing foreign genes. The biomass of the MNR$p r p R$ and MNR-prpDBC were lower than the MNR and

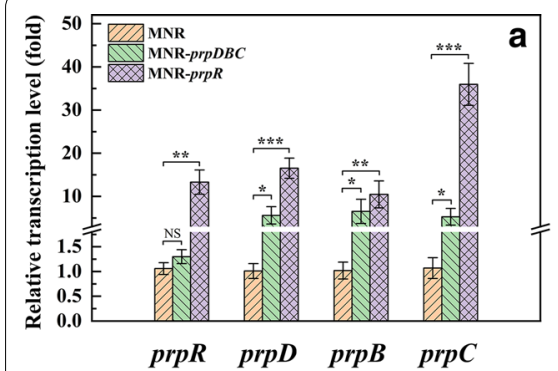

Fig. 2 Recombinant strain qRT-PCR analysis, growth status, and AD conversion ratio of MNR, MNR-prpR and MNR-prpDBC. a qRT-PCR analysis of the expression variations of $\operatorname{prpR}$, $p r p D, \operatorname{prpB}$ and $p r p C$. $\mathbf{b}$ Growth curves of MNR, MNR-prpR, and MNR-prpDBC. $\mathbf{c}$ Time courses of biotransformation rates of $A D$ by MNR, MNR-prpR, and MNR-prpDBC. Error bars indicate the standard deviation from three independent experiments and the levels of statistical significance are indicated as follows: ${ }^{*} p<0.05 ;{ }^{* *} p<0.01 ;{ }^{* *} p<0.001$; NS, indicates no significant difference $(p>0.05)$ 
control strain, and MNR-prpR had the smallest biomass (Fig. 2b). As shown in Fig. 2c, the AD production capacity of recombinant strains was higher than that of MNR and MNR-pMV261. The highest AD molar conversion rates of MNR-prpR and MNR-prpDBC were $90.6 \pm 2.6 \%$ and $82.2 \pm 2.2 \%$, respectively, which were higher than the parental strain $(72.3 \pm 2.5 \%)$ and control strain (70.1 $\pm 2.7 \%)$. The AD conversion rate of MNR-prpDBC was always lower than that of MNR and MNR-pMV261 before $48 \mathrm{~h}$, and the conversion rate of MNR-pMV261 was consistently lower than that of MNR. The main reason for this phenomenon may be due to the increased metabolic load caused by the generation of antibiotic resistance and genes overexpression. The above results showed that the overexpression of prp operon enhanced the AD production capacity of MNR, and the effect of prpR overexpression was most evident.

\section{Enhancement of the $M C C$ can reduce the accumulation} of propionyl-CoA in cells and increase the viability of bacteria The MNR, MNR-prpR and MNR-prpDBC intracellular propionyl-CoA level assays showed that the recombinant strains had similar trends to the parental strains. The overexpression of the $p r p R$ and $p r p D B C$ can effectively reduce the accumulation of propionyl-CoA in the middle and late stages of biotransformation (Fig. 3a), and the MNR-prpR has the lowest intracellular propionyl-CoA level. At $96 \mathrm{~h}$, intracellular levels of propionylCoA in MNR-prpR and MNR-prpDBC (5.9 \pm 0.5 and $7.8 \pm 0.6 \mu \mathrm{M})$ were reduced by $43 \pm 3 \%$ and $23 \pm 4 \%$ compared to MNR $(10.2 \pm 0.9 \mu \mathrm{M})$. Moreover, the cell viability of recombinant strains was improved. The MNR$\operatorname{prpR}$ always showed higher cell viability than MNR and MNR-prpDBC (Fig. 3b). The highest cell viability of MNR-prpR $(1.6 \pm 0.04)$ was $22 \pm 1 \%$ higher than that of
MNR (1.3 \pm 0.04$)$. Although the cell survival rates of the three strains decreased after $96 \mathrm{~h}, \mathrm{MNR}-\mathrm{prpR}$ and MNR$\operatorname{prp} D B C$ showed a slower downward trend than MNR. At $144 \mathrm{~h}$, the cell viability of MNR was only $53 \pm 1 \%$ of the highest value, whereas the ratio of MNR-prpR was $83 \pm 1 \%$. In $M$. tuberculosis, MCC is essential for growth on propionate or cholesterol. Masiewicz et al. [26] confirmed that PrpR as a transcription factor is directly involved in the regulation of genes encoding the key enzymes of methylcitrate $\operatorname{PrpD}, \operatorname{PrpC}$ and isocitrate lyase Icl1 cycles. The deletion of the prpR genes results in impaired growth in vitro on propionate or cholesterol as a sole carbon source. Similar results were obtained for non-pathogenic M. smegmatis [19].

The MCC plays an essential role in the detoxification of propionyl-CoA in mycobacteria. The overexpression of the prp operon can enhance the MCC, reduce the intracellular accumulation of propionyl-CoA and maintain cell viability. The reduction of propionyl-CoA also has a promoting effect on the side chain degradation of phytosterols, effectively improving the AD production capacity of MNR.

\section{The function of $g \ln R$ in MNR glnR expression repressed the transcription of prpDBC}

In the study of the effects of different nitrogen sources on the conversion of phytosterols by MNR, diammonium phosphate was found to be an excellent inorganic nitrogen source to replace yeast extracts. The optimum amount of $\left(\mathrm{NH}_{4}\right)_{2} \mathrm{HPO}_{4}$ for use was $3.5 \mathrm{~g} / \mathrm{L}$, and the yield of $\mathrm{AD}$ decreased significantly with the decrease of $\left(\mathrm{NH}_{4}\right)_{2} \mathrm{HPO}_{4}$ usage (data not shown). During the growth of $M$. smegmatis, nitrogen restriction increases the level of $g \ln R$ transcription and inhibits the transcription of $\operatorname{prp} D B C$ involved in the
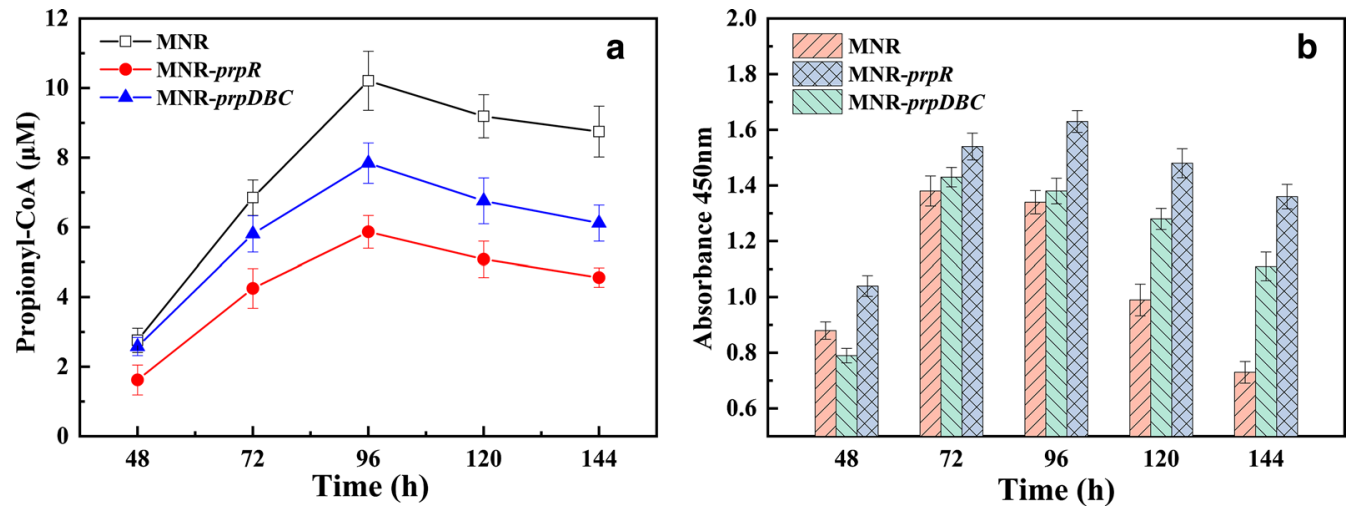

Fig. 3 Intracellular propionyl-CoA level and cell viability of MNR, MNR-prpR and MNR-prpDBC. a Propionyl-CoA levels of strains in the biotransformation process. $\mathbf{b}$ Cell viability of strains in the biotransformation process. Error bars indicate the standard deviation from three independent experiments 
MCC [36]. Inspired by this, the transcriptional levels of $g \ln R$ and $\operatorname{prpDBC}$ in MNR were studied at different nitrogen source levels. As shown in Fig. 4a, the $g \ln R$ transcription level increased $12.9 \pm 1.4$-fold at the nitrogen-limited level $\left(\mathrm{N}^{0.1}\right)$, but a $96 \pm 1 \%$ decrease for prpD, a $71 \pm 2 \%$ decrease for prpB, and a $91 \pm 1 \%$ decrease for prpC. At a low nitrogen source level $\left(\mathrm{N}^{0.5}\right)$, the same trend was observed for prp operon. A $\operatorname{prpR}$ knockout $(\mathrm{MNR} \triangle g \ln R)$ and a replenishing strain (MNR $\triangle g \ln R:: \operatorname{gln} R)$ were constructed and used in further confirming the effect of PrpR on the transcription of $\operatorname{prp} D B C$. The transcription levels of $\operatorname{prp} D B C$ genes were studied under $\mathrm{N}^{0.1}$ conditions (Fig. 4b). Compared with MNR, the deletion of $g \ln R$ resulted in increased $\operatorname{prpD}, \operatorname{prp} B$ and $\operatorname{prp} C$ transcripts by $3.3 \pm 0.6,2.2 \pm 0.5$ and $9.6 \pm 1.1$ times, respectively.

The transcription levels of prpDBC in MNR $\Delta g \ln R:: g \ln R$ were equivalent to that in MNR. These results further demonstrated that GlnR inhibited the transcription of $\operatorname{prpDBC}$ involved in the MCC in response to stress from low nitrogen sources. These findings were consistent with previous reports, the deletion of $g \ln R$ alleviates the GlnR-mediated repression of prpDBC and increases the activity of the MCC (assimilation of propanoate and propionyl-CoA) [36].
Effects of deleting gInR on cell growth and biotransformation The existing data indicate $g \ln R$ is a global transcriptional regulator. In Saccharopolyspora erythraea, $g \ln R$ can not only regulate nitrogen metabolism, but also regulate carbon metabolism [42] and homeostasis of intracellular phosphorus [43], and affects the synthesis of actinomycete antibiotics in Streptomyces [44]. Recent studies showed that GlnR inhibits the transcription of the prpDBC involved in the MCC at low nitrogen levels. The findings revealed a unique link between nitrogen metabolism and propionyl-CoA assimilation involved in fatty acid or cholesterol utilization [36]. The GlnR responds to low nitrogen source levels and inhibits $p r p D B C$. PrpD, PrpB and PrpC are the core enzymes of MCC and play an important role in the metabolism of propionyl-CoA. The overexpression of $p r p$ operon in MNR $\Delta g \ln R$ affects the AD production of MNR. The prpR and prpDBC overexpression strains of MNR $\Delta g \ln R$ (MNR-prpR/ $\Delta g \ln R$ and MNR-prpDBC/ $\triangle g \ln R$ ) were constructed, and the cell growth and biotransformation of different strains were studied at different levels of nitrogen sources. As shown in Table 2, all strains had low biomass and biotransformation rates under $\mathrm{N}^{0.1}$ conditions. With the increase nitrogen source level, the two indices of each strain increased significantly. At the same nitrogen source level,
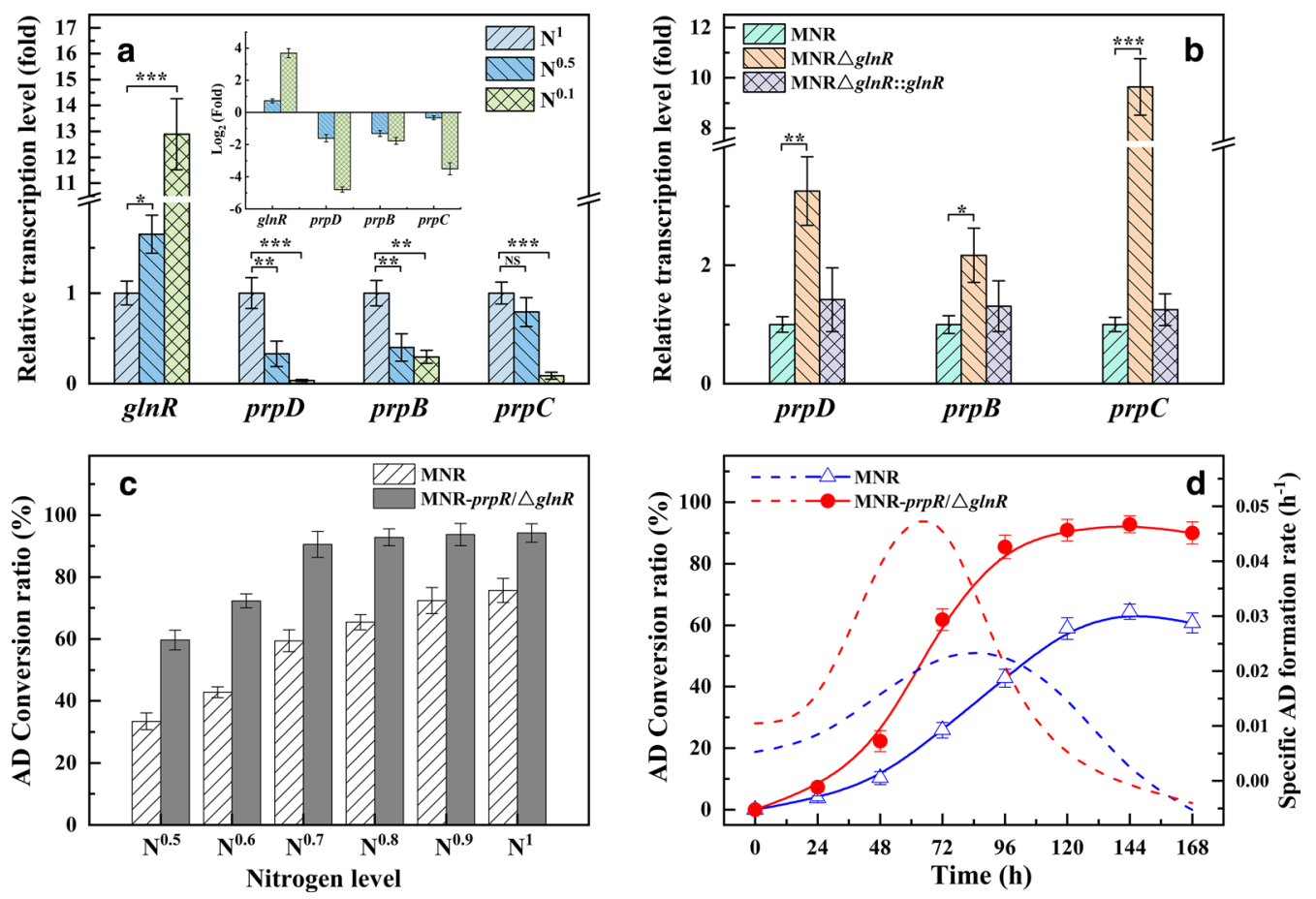

Fig. 4 The function of $g \ln R$ in MNR. a The transcription of $\operatorname{prp} D B C$ is responsive to nitrogen availability. $\mathbf{b}$ GlnR represses the transcription of $p r p D B C$ in MNR. c Optimization of the addition of nitrogen levels for AD production. $\mathbf{d}$ Time course of AD production by MNR-prpR/ $\triangle \mathrm{g} / \mathrm{nR}$ in low nitrogen levels. Error bars indicate the standard deviation from three independent experiments and the levels of statistical significance are indicated as follows: ${ }^{*} p<0.05 ;{ }^{* *} p<0.01 ;{ }^{* *} p<0.001$ 
Table 2 Recombinant strain growth status and AD conversion ratio in different levels of nitrogen sources

\begin{tabular}{|c|c|c|c|c|c|c|}
\hline \multirow[t]{2}{*}{ Strains } & \multicolumn{2}{|c|}{$\mathrm{N}^{0.1}\left(0.35 \mathrm{~g} / \mathrm{L} \mathrm{NH}_{42} \mathrm{PO}_{4}\right)$} & \multicolumn{2}{|c|}{$\mathrm{N}^{0.5}\left(1.75 \mathrm{~g} / \mathrm{L} \mathrm{NH}_{42} \mathrm{PO}_{4}\right)$} & \multicolumn{2}{|c|}{$\mathrm{N}^{1}\left(3.5 \mathrm{~g} / \mathrm{L} \mathrm{NH}_{42} \mathrm{PO}_{4}\right)$} \\
\hline & Final $O D_{600}$ & $\begin{array}{l}\text { Max AD } \\
\text { converted (\%) }\end{array}$ & Final $O D_{600}$ & $\begin{array}{l}\text { Max AD } \\
\text { converted (\%) }\end{array}$ & Final $O D_{600}$ & $\begin{array}{l}\text { Max AD } \\
\text { converted } \\
(\%)\end{array}$ \\
\hline MNR & $6.5 \pm 0.2$ & $13.8 \pm 2.8$ & $10.3 \pm 0.3$ & $42.4 \pm 2.7$ & $11.5 \pm 0.6$ & $75.7 \pm 3.5$ \\
\hline$M N R \triangle g \ln R$ & $7.0 \pm 0.3$ & $16.7 \pm 2.3$ & $10.8 \pm 0.4$ & $49.3 \pm 2.3$ & $10.8 \pm 0.5$ & $86.3 \pm 3.7$ \\
\hline MNR-prpDBC/ $\triangle g \mid n R$ & $6.8 \pm 0.2$ & $17.3 \pm 2.5$ & $10.3 \pm 0.3$ & $52.3 \pm 2.8$ & $10.2 \pm 0.5$ & $91.7 \pm 3.6$ \\
\hline MNR-prpR/ $\Delta g \ln R$ & $6.7 \pm 0.2$ & $21.6 \pm 2.4$ & $10.8 \pm 0.4$ & $57.7 \pm 2.8$ & $11.2 \pm 0.6$ & $94.3 \pm 3.4$ \\
\hline
\end{tabular}

$g \ln R$ deletion was beneficial to the transformation of phytosterols, and the overexpression of prp operon gene cluster can further enhance the transformation ability of MNR. Consistent with the above results, the overexpression of $p r p R$ in $g \ln R$-deleted strains was more effective than prpDBC. Under the conditions of $\mathrm{N}^{0.1}, \mathrm{~N}^{0.5}$ and $\mathrm{N}^{1}$, the biotransformation rates of $\mathrm{MNR}-\mathrm{prpR} / \Delta g \ln R$ were $21.6 \pm 2.4 \%, 57.7 \pm 2.8 \%$ and $94.3 \pm 3.4 \%$, which were 1.6, 1.4 and 1.2 times higher than MNR (13.8 $\pm 2.8 \%$, $42.4 \pm 2.7$ and $75.7 \pm 3.5$ ), respectively. These results indicated that the nitrogen source level is an important factor affecting the cell growth and AD production of MNR. At low nitrogen level, the deletion of $g \ln R$ relieved the inhibition of $G \ln R$ on $\operatorname{prpDBC}$ and increased the metabolism of propionyl-CoA by MCC.

\section{Effect of different nitrogen sources levels on the $A D$ production of MNR-prpR/ $\Delta g \ln R$}

The impact of varying nitrogen source levels on the AD production of MNR and MNR-prpR/ $\Delta g \ln R$ were investigated in a shake flask. The result was used in studying the feasibility of reducing the cost of nitrogen sources. The biotransformation rates of MNR and MNR-prpR/ $\Delta g \ln R$ increased with nitrogen source level from $\mathrm{N}^{0.5}$ to $\mathrm{N}^{1}$ (Fig. 4c). The $\mathrm{AD}$ biotransformation rates of MNR-prpR/ $\Delta g \ln R(90.6 \pm 4.2 \%)$ under $\mathrm{N}^{0.7}$ condition was 1.2 times than that of MNR under $\mathrm{N}^{1}$ condition (75.7 $\pm 3.9 \%)$. The AD biotransformation rates of MNR$\operatorname{prpR} / \Delta g \ln R$ increased slightly with nitrogen content. The AD conversion rates of MNR-prpR/ $\Delta g \ln R$ were $92.8 \pm 2.7 \%, \quad 93.7 \pm 3.6 \%$ and $94.2 \pm 3.0 \%$ under $\mathrm{N}^{0.8}$, $\mathrm{N}^{0.9}$ and $\mathrm{N}^{1}$ conditions, respectively. Therefore, in subsequent experiments, $\mathrm{N}^{0.7}$ conditions were selected for the investigation of the phytosterol biotransformation of MNR-prpR/ $\Delta g \ln R$. As shown in Fig. 4d, compared with MNR, MNR-prpR/ $\Delta g \ln R$ had higher phytosterol biotransformation ability during fermentation. At $144 \mathrm{~h}$, the highest biotransformation rate of MNR-prpR/ $\Delta g \ln R$ was $92.8 \pm 2.7 \%$, which was $28.4 \pm 1.0 \%$ higher than that of MNR $(64.4 \pm 2.5 \%)$. A comparison of the AD formation rate $\left(q_{p}\right)$ of MNR and MNR $\Delta$ glnR-prpR showed that the highest $q_{p}(0.045)$ of MNR $\Delta$ glnR-prpR at $72 \mathrm{~h}$ was 2 times higher than the highest $q_{p}(0.023)$ of MNR at $96 \mathrm{~h}$. Moreover, the production time for the highest $q_{p}$ for MNR $\Delta$ glnR-prpR was shorter by $24 \mathrm{~h}$. Therefore, the AD production performance of $M N R \Delta g \ln R-p r p R$ is better than that of MNR at the low nitrogen source level.

\section{A novel strategy for improving phytosterol biotransformation in low nitrogen levels by the transcriptional regulators PrpR and GInR}

Our previous studies showed that the enhancement of the propionyl-CoA carboxylase gene in the MMC of propionyl-CoA metabolism could improve the ability of MNR to transform phytosterols. In the present study, based on the identification of prp operon and $g \ln R$ in MNR, a novel strategy of improving phytosterol biotransformation in a low nitrogen level was established (Fig. 5). In MNR, the overexpression of the prp operon enhanced $\mathrm{MCC}$ to reduce the accumulation of propionyl-CoA and its endotoxic, thus, enabling the strains to maintain high activity to achieve efficient production of AD. The combination strategy of knocking out $g \ln R$ and overexpressing $\operatorname{prp} R$ can eliminate the inhibitory effect of $g \ln R$ on $\operatorname{prp} D B C$, increase the low nitrogen adaptation ability of MNR and enable the MNR-prpR/ $\Delta g \ln R$ to produce AD efficiently under low nitrogen sources.

\section{Conclusions}

In this study, we identified the prp operon and the $g \ln R$ in MNR and studied the regulatory effects of PrpR and GlnR on $p r p D, p r p B$ and $p r p C$. The enhancement of $p r p R$ and $\operatorname{prp} D B C$ can effectively reduce the accumulation of propionyl-CoA and enhance the phytosterol biotransformation ability of MNR. Besides, $g \ln R$-deficient strains can better adapt to a low nitrogen source environment and reduce nitrogen source consumption in AD production. These findings provide new insights into the enhancement of the production capacity of steroid precursors of mycobacteria and the reduction of the cost of using nitrogen sources. 


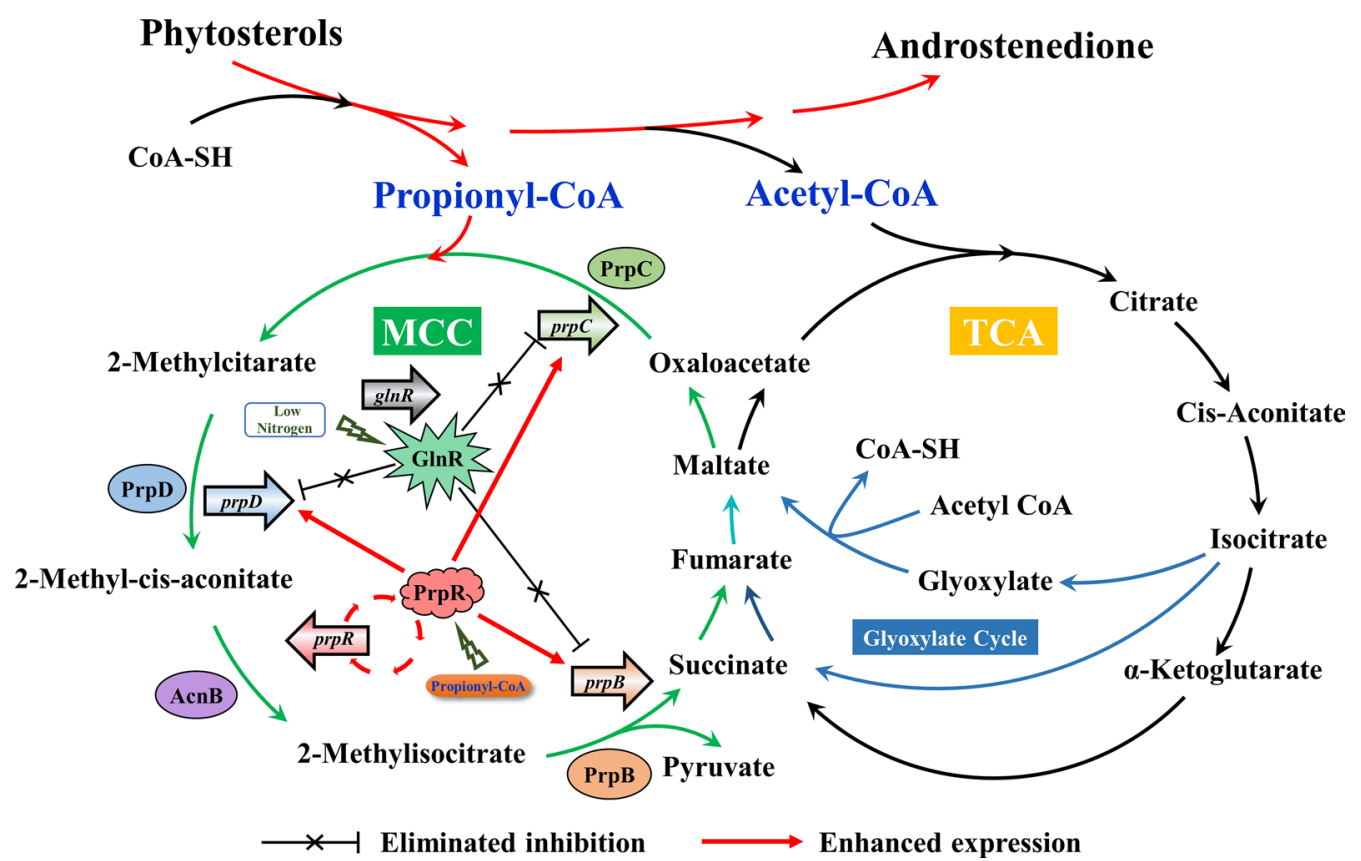

Fig. 5 The regulatory mechanism of $G \ln R$ and PrpR on prpDBC involved in the methylcitrate cycle pathway of MNR

\section{Abbreviations}

AD: androstenedione; 9a-OH-AD: 9a-hydroxyandrostenedione; MNR Mycobacterium neoaurum; MFT: Mycobacterium fortuitum; prpC: methylcitrate synthase gene; prpD: methylcitrate dehydratase/hydratase gene; $p r p B$ methylisocitrate lyase gene; MMC: methyl citrate cycle; $p r p R:$ propionate regulator PrpR gene; gInR: nitrogen transcription regulator GlnR gene; CoA: coenzyme A; DCW: dry cell weight; ROS: reactive oxygen species; MCC: 2-methylcitrate cycle pathway; LB: Luria-Bertani; Kan: kanamycin resistance; qRT-PCR: quantitative Reverse Transcription-PCR; mRNA: messenger RNA; PBS: phosphate-buffered saline; HPLC: high-performance liquid; AcnD: methylcitrate dehydratase; PrpF: methylaconitate cis-trans isomerase; AcnB: aconitase.

\section{Acknowledgements}

Not applicable.

\section{Authors' contributions}

$Y Z$ and $X Z$ contributed equally to this work. YZ and XZ performed most of the experiments, data analyses, and interpretation. YS designed and supervised the research and edited the manuscript aspects of this work. XW and LW designed and participated in the experimental aspects of this work. MX and $J L$ helped edit the manuscript. MW supervised the research and edited the manuscript. All authors read and approved the final manuscript.

\section{Funding}

This work was supported by the National Key R\&D Program of China, Synthetic Biology Research (Grant No. 2019YFA0905300), the National Natural Science Foundation of China (Grant No. 21978221), the China Postdoctoral Science Foundation (Grant No. 2018M631748), the Innovation Project of Excellent Doctorial Dissertation of Tianjin University of Science and Technology (Grant No. 2019007), the Foundation of Key Laboratory of Industrial Fermentation Microbiology of Ministry of Education and Tianjin Key Laboratory of Industrial Microbiology (Grant No. 2018KF007), and the Natural Science Foundation of Shandong Province of China (No. ZR2018QC002).

\section{Availability of data and materials}

All data generated or analyzed in this study are included in the published article.
Ethics approval and consent to participate

This article does not contain any studies involving human or animal participants.

\section{Consent for publication}

Not applicable.

\section{Competing interests}

The authors declare that they have no competing interests.

Received: 18 October 2019 Accepted: 16 January 2020

Published online: 28 January 2020

\section{References}

1. Donova MV, Egorova OV. Microbial steroid transformations: Current state and prospects. Appl Microbiol Biotechnol. 2012;94:1423-47.

2. Fernández-Cabezón L, Galán B, García JL. New insights on steroid biotechnology. Front Microbiol. 2018;9:958.

3. Malaviya A, Gomes J. Androstenedione production by biotransformation of phytosterols. Bioresour Technol. 2008;99:6725-37.

4. Xiong $\mathrm{L}$, Liu $\mathrm{H}$, Xu L, et al. Role identification and application of SigD in the transformation of soybean phytosterol to 9a-Hydroxy-4androstene-3,17-dione in Mycobacterium neoaurum. J Agric Food Chem. 2017;65:626-31.

5. Zhang R, Liu X, Wang Y, et al. Identification, function, and application of 3-ketosteroid $\Delta 1$-dehydrogenase isozymes in Mycobacterium neoaurum DSM 1381 for the production of steroidic synthons. Microb Cell Fact. 2018:17:77.

6. Yao K, Xu LQ, Wang FQ, et al. Characterization and engineering of 3-ketosteroid- $\Delta 1$-dehydrogenase and 3-ketosteroid-9a-hydroxylase in Mycobacterium neoaurum ATCC 25795 to produce 9a-hydroxy-4androstene-3,17-dione through the catabolism of sterols. Metab Eng. 2014;24:181-91.

7. Shao M, Zhang X, Rao Z, et al. A mutant form of 3-ketosteroid- $\Delta 1$ dehydrogenase gives altered androst-1,4-diene-3,17-dione/androst-4ene-3,17-dione molar ratios in steroid biotransformations by Mycobacterium neoaurum ST-095. J Ind Microbiol Biotechnol. 2016;43:691-701. 
8. Xiong $L$, Liu H, Xu L, et al. Improving the production of 22-hydroxy23,24-bisnorchol-4-ene-3-one from sterols in Mycobacterium neoaurum by increasing cell permeability and modifying multiple genes. Microb Cell Fact. 2017;16:89.

9. Shao M, Zhang X, Rao Z, et al. Identification of steroid C27 monooxygenase isoenzymes involved in sterol catabolism and stepwise pathway engineering of Mycobacterium neoaurum for improved androst-1,4-diene-3,17-dione production. J Ind Microbiol Biotechnol. 2019;46:635-47.

10. Wang $X$, Feng J, Zhang $D$, et al. Characterization of new recombinant 3-ketosteroid- $\triangle 1$-dehydrogenases for the biotransformation of steroids. Appl Microbiol Biotechnol. 2017;101:6049-60.

11. Yao K, Wang FQ, Zhang HC, et al. Identification and engineering of cholesterol oxidases involved in the initial step of sterols catabolism in Mycobacterium neoaurum. Metab Eng. 2013;15:75-877.

12. Sun W, Wang $L$, Liu H, et al. Characterization and engineering control of the effects of reactive oxygen species on the conversion of sterols to steroid synthons in Mycobacterium neoaurum. Metab Eng. 2019;56:97-110.

13. Zhou X, Zhang Y, Shen Y, et al. Efficient production of androstenedione by repeated batch fermentation in waste cooking oil media through regulating $\mathrm{NAD}+/ \mathrm{NADH}$ ratio and strengthening cell vitality of Mycobacterium neoaurum. Bioresour Technol. 2019;279:209-17.

14. Yang $X$, Nesbitt NM, Dubnau E, et al. Cholesterol metabolism increases the metabolic pool of propionate in Mycobacterium tuberculosis. Biochemistry. 2009;48:3819-21.

15. Liu M, Xiong L, Tao X, et al. Metabolic adaptation of Mycobacterium neoaurum ATCC 25795 in the catabolism of sterols for producing important steroid intermediates. J Agric Food Chem. 2018;66:12141-50.

16. Griffin JE, Pandey AK, Gilmore SA, et al. Cholesterol catabolism by Mycobacterium tuberculosis requires transcriptional and metabolic adaptations. Chem Biol. 2012;19:218-27.

17. Szentirmai A. Microbial physiology of sidechain degradation of sterols. J Ind Microbiol. 1990;6:101-15.

18. Eoh $\mathrm{H}$, Rhee KY. Methylcitrate cycle defines the bactericidal essentiality of isocitrate lyase for survival of Mycobacterium tuberculosis on fatty acids. Proc Natl Acad Sci. 2014;111:4976-81.

19. Upton AM, McKinney JD. Role of the methylcitrate cycle in propionate metabolism and detoxification in Mycobacterium smegmatis. Microbiology. 2007;153:3973-82.

20. Savvi S, Warner DF, Kana BD, et al. Functional Characterization of a vitamin B12-dependent methylmalonyl pathway in Mycobacterium tuberculosis: implications for propionate metabolism during growth on fatty acids. J Bacteriol. 2008;190:3886-955.

21. Zhou $X$, Zhang $Y$, Shen $Y$, et al. Economical production of androstenedione and 9a-hydroxyandrostenedione using untreated cane molasses by recombinant mycobacteria. Bioresour Technol. 2019;290:121750.

22. Claes WA, Puhler A, Kalinowski J. Identification of Two prpDBC gene clusters in Corynebacterium glutamicum and their involvement in propionate degradation via the 2-methylcitrate cycle. J Bacteriol. 2002;184:2728-39.

23. Bramer CO, Silva LF, Gomez JGC, et al. Identification of the 2-methylcitrate pathway involved in the catabolism of propionate in the polyhydroxyalkanoate-producing strain Burkholderia sacchari IPT101T and analysis of a mutant accumulating a copolyester with higher 3-hydroxyvalerate content. Appl Environ Microbiol. 2002;68:271-9.

24. Textor S, Wendisch VF, De GAA, et al. Propionate oxidation in Escherichia coli: evidence for operation of a methylcitrate cycle in bacteria. Arch Microbiol. 1997;168:428-36.

25. Munoz-Elias EJ, Upton AM, Cherian J, et al. Role of the methylcitrate cycle in Mycobacterium tuberculosis metabolism, intracellular growth, and virulence. Mol Microbiol. 2006;60:1109-22.

26. Masiewicz P, Brzostek A, Wolański M, et al. A novel role of the PrpR as a transcription factor involved in the regulation of methylcitrate pathway in Mycobacterium tuberculosis. PLoS ONE. 2012;7:e43651.
27. Deschoenmaeker F, Bayon-Vicente G, Sachdeva N, et al. Impact of different nitrogen sources on the growth of Arthrospira sp. PCC 8005 under batch and continuous cultivation - a biochemical, transcriptomic and proteomic profile. Bioresour Technol. 2017;237:78-88.

28. Lozano Terol G, Gallego-Jara J, Sola Martínez RA, et al. Engineering protein production by rationally choosing a carbon and nitrogen source using E. coli BL21 acetate metabolism knockout strains. Microb Cell Fact. 2019;18:151.

29. Dang Y, Zhao F, Liu X, et al. Enhanced production of antifungal lipopeptide iturin A by Bacillus amyloliquefaciens LL3 through metabolic engineering and culture conditions optimization. Microb Cell Fact. 2019;18:68.

30. Cheng C, Zhou Y, Lin M, et al. Polymalic acid fermentation by Aureobasidium pullulans for malic acid production from soybean hull and soy molasses: fermentation kinetics and economic analysis. Bioresour Technol. 2017;223:166-74.

31. Kamzolova SV, Morgunov IG. Biosynthesis of pyruvic acid from glycerolcontaining substrates and its regulation in the yeast Yarrowia lipolytica. Bioresour Technol. 2018;266:125-33.

32. Bukhari NA, Loh SK, Nasrin AB, et al. Compatibility of utilising nitrogenrich oil palm trunk sap for succinic acid fermentation by Actinobacillus succinogenes 130Z. Bioresour Technol. 2019;293:122085.

33. Yao L, Liao C, Huang G, et al. GInR-mediated regulation of nitrogen metabolism in the actinomycete Saccharopolyspora erythraea. Appl Microbiol Biotechnol. 2014;98:7935-48.

34. Yang Y, Richards JP, Gundrum J, et al. GlnR activation induces peroxide resistance in mycobacterial biofilms. Front Microbiol. 2018;9:1428.

35. Jenkins VA, Barton GR, Robertson BD, et al. Genome wide analysis of the complete GInR nitrogen-response regulon in Mycobacterium smegmatis. BMC Genomics. 2013;14:301.

36. Liu W, Liu X, Shen M, et al. The nitrogen regulator GlnR directly controls transcription of the prpDBC operon involved in methylcitrate cycle in Mycobacterium smegmatis. J Bacteriol. 2019;201:e00099-e119.

37. Song B, Zhou Q, Xue HJ, et al. IrrE improves organic solvent tolerance and $\triangle 1$-dehydrogenation productivity of arthrobacter simplex. J Agric Food Chem. 2018:66:5210-20.

38. Xu J, Wu Z, Gao S, et al. Rational modification of tricarboxylic acid cycle for improving L-lysine production in Corynebacterium glutamicum. Microb Cell Fact. 2018;17:105.

39. Livak KJ, Schmittgen TD. Analysis of relative gene expression data using real-time quantitative PCR and the $2-\triangle \triangle C T$ method. Methods. 2001;25:402-8.

40. Su L, Shen Y, Zhang W, et al. Cofactor engineering to regulate NAD+/ $\mathrm{NADH}$ ratio with its application to phytosterols biotransformation. Microb Cell Fact. 2017;16:182.

41. Xu Z, Wang M, Ye B. TetR family transcriptional regulator PccD negatively controls propionyl coenzyme A assimilation in Saccharopolyspora erythraea. J Bacteriol. 2017;199:e00281-e317.

42. Liao C-H, Yao L, Xu Y, et al. Nitrogen regulator $G \ln R$ controls uptake and utilization of non-phosphotransferase-system carbon sources in actinomycetes. Proc Natl Acad Sci. 2015;112:201508465.

43. Yao $L, Y e B$. Reciprocal regulation of $G \ln R$ and PhoP in response to nitrogen and phosphate limitations in Saccharopolyspora erythraea. Appl Environ Microbiol. 2016;82:409-20.

44. He JM, Zhu H, Zheng GS, et al. Direct involvement of the master nitrogen metabolism regulator $\mathrm{GlnR}$ in antibiotic biosynthesis in streptomyces. J Biol Chem. 2016;291:26443-54.

\section{Publisher's Note}

Springer Nature remains neutral with regard to jurisdictional claims in published maps and institutional affiliations. 